\title{
A Vague Understanding of the Biology and Epidemiology of Echinococcosis by Dog Owners in Hokkaido, an Endemic Island for Echinococcus multilocularis in Japan
}

\author{
Nariaki NONAKA ${ }^{1) *}$, Masao KAMIYA ${ }^{2)}$ and Yuzaburo OKU ${ }^{1)}$ \\ ${ }^{1)}$ Laboratory of Parasitology, Department of Disease Control, Graduate School of Veterinary Medicine, Hokkaido University, Kita-ku Kita \\ 18 Nishi 9, Sapporo 060-0818 and ${ }^{2)}$ OIE Reference Laboratory for Echinococcosis, Laboratory of Environmental Zoology, Department \\ of Biosphere and Environmental Sciences, Faculty of Environment Systems, Rakuno-Gakuen University, Bunkyo-dai Midori-machi 582 , \\ Ebetsu 069-0836, Japan
}

(Received 14 July 2008/Accepted 20 August 2008)

ABSTRACT. A questionnaire survey was conducted by giving 14 statements about echinococcosis to 2,070 dog owners residing in Hokkaido in order to evaluate their understanding about the biology and epidemiology of Echinococcus multilocularis. Analysis of the answers revealed that dog owners understood the disease superficially, and there were several points of confusion in their understanding, especially regarding differences in the modes of transmission and disease development in dogs and humans. The results suggest the need for the proper education of dog owners to perform proper prophylactic measures against the disease.

KEY WORDS: canine, Echinococcus, epidemiology, parasitic zoonoses, zoonosis.

J. Vet. Med. Sci. 71(1): 105-107, 2009

Echinococcus multilocularis is distributed in the northern hemisphere, including Hokkaido, Japan. If humans accidentally ingest the parasite eggs and become infected, the parasite metacestodes develop in the liver and occasionally in other organs and cause a lethal disease, alveolar echinococcosis [10]. The parasite is primarily maintained in the sylvatic cycle, with foxes serving as definitive (final) hosts and voles serving as intermediate hosts. In endemic regions, dogs can also become a final host, serving as a potential infectious source to humans $[1,2,4,5,7,11]$. Therefore, prophylaxis for dog infection is of high importance for risk management of the infection to humans, especially for dog owners [6].

In Hokkaido, the prevalence of infection in foxes has been approximately $40 \%$ during the last two decades [9]. By 2007, 531 human patients had been identified (data from the Hokkaido government). However, the routes of infection to humans have not been completely clarified $[3,10]$. One possible route of infection that should be considered is via infected pet dogs. In our survey conducted from 1997 to 2007 to determine the prevalence of infection in pet dogs, $0.4 \%$ of the dogs examined $(n=4,768)$ excreted taeniid eggs that were identified as E. multilocularis eggs by PCR examination of egg DNA [8]. To control echinococcosis, the Hokkaido government has been conducting surveys and countermeasures, including annual surveys on the prevalence of infection in foxes and other animals, development of diagnostic and therapeutic measures for human patients, and education of residents through schools and publications.

In this study, we conducted a simple questionnaire survey of dog owners who requested us to test their dogs for E. mul-

\footnotetext{
* CoRrespondence to: NonaKa, N. (present address), Laboratory of Veterinary Parasitology, Department of Veterinary Sciences, Faculty of Agriculture, University of Miyazaki, Gakuen-Kihanadai Nishi 1-1, Miyazaki 889-2192, Japan.

e-mail:nnonaka@cc.miyazaki-u.ac.jp
}

tilocularis infection in order to assess how precisely dog owners who have a potentially high risk of infection understand the biology and epidemiology of echinococcosis.

From 1997 to 2004, the questionnaire was conducted by giving 9 or 14 statements on the biology and epidemiology of echinococcosis to $2,070 \mathrm{dog}$ owners residing in Hokkaido, who were asked to answer whether each statement is Right, Wrong, or Unknown (Table 1). More than $50 \%$ of the dog owners answered statements S1 to S8 correctly. Most of those statements contained descriptions of the basic biology and epidemiology of echinococcosis in Hokkaido, and the dog owners seemed to understand well the current situation of the disease in Hokkaido and the general mode of transmission. In contrast, less than $50 \%$ of the dog owners answered statements S9 to S14 correctly. In particular, less than $20 \%$ answered S13 and S14 correctly and more than $50 \%$ answered incorrectly.

Statements S4, S12, and S14 were related to the transmission of the parasite to dogs. Among the dog owners who answered S4 correctly, the percentages of owners that answered S12 correctly and incorrectly were $48.2 \%$ and $32.3 \%$, respectively. For statement S14, the percentages were $24.2 \%$ and $60.4 \%$, respectively. The results indicate that most dog owners understood that dogs get the infection by ingesting infected rodents; however, their understanding was vague, and many dog owners thought that dogs also get the infection from foxes, presumably by ingesting the parasite eggs excreted from foxes. One possible reason for this misunderstanding could be confusion regarding the two different modes of transmission to dogs and humans. In another words, many dog owners misunderstood an important characteristic of the parasite life cycle: transmission never directly occurs between two final hosts, such as fox and dog.

Regarding their understanding of the transmission to humans, $69.1 \%$ of the dog owners understood that humans 
Table 1. Questions about echinococcosis in Hokkaido given to dog owners and the percentage of correct answers

\begin{tabular}{|c|c|c|c|c|c|}
\hline $\begin{array}{l}\text { Statement } \\
\text { No. }\end{array}$ & Statement & No. answered & $\begin{array}{l}\text { Correct } \\
\text { answer }\end{array}$ & $\begin{array}{l}\text { Percentage } \\
\text { correct answer }\end{array}$ & $\begin{array}{l}\text { Percentage of } \\
\text { incorrect answer }\end{array}$ \\
\hline$S 1^{\text {a) }}$ & Infected foxes inhabit Sapporo ${ }^{\text {b). }}$ & 448 & Right & 87.9 & 0.4 \\
\hline $\mathrm{S}^{\mathrm{a})}$ & The disease is now spread all over Hokkaido. & 382 & Right & 87.2 & 3.9 \\
\hline $\mathrm{S} 3$ & $\begin{array}{l}\text { The parasite eggs in the feces of infected dogs can be } \\
\text { an infectious source to humans. }\end{array}$ & 2013 & Right & 86.4 & 3.4 \\
\hline S4 & Dogs are infected by ingesting infected rodents. & 2008 & Right & 80.1 & 10.3 \\
\hline $\mathrm{S} 5^{\mathrm{a})}$ & $\begin{array}{l}\text { Rodents playing a role in the transmition of } \\
\text { the disease are those found in houses. }\end{array}$ & 445 & Wrong & 74.6 & 6.5 \\
\hline S6 & Humans get the infection by ingesting the parasite eggs. & 1998 & Right & 69.1 & 15.9 \\
\hline S7 & Infected dogs have to be euthanized in Hokkaido. & 1988 & Wrong & 60.9 & 3.3 \\
\hline $\mathrm{S} 8^{\mathrm{a})}$ & The parasite eggs can be killed by boiling them. & 444 & Right & 52.7 & 15.5 \\
\hline S9 & $\begin{array}{l}\text { Infected dogs can be dewormed completely with an } \\
\text { anthelmintic drug. }\end{array}$ & 1985 & Right & 49.7 & 17.1 \\
\hline S10 & The disease never transmits from human to human. & 1995 & Right & 48.9 & 26.1 \\
\hline S11 & Humans also get infection by ingesting infected pigs. & 1986 & Wrong & 44.6 & 22.4 \\
\hline $\mathrm{S} 12$ & Dogs are infected by physical contact with infected foxes. & es. 1997 & Wrong & 44.5 & 33.0 \\
\hline $\mathrm{S} 13$ & Infected dogs have parasitic legions in the liver. & 1997 & Wrong & 19.7 & 50.5 \\
\hline $\mathrm{S} 14^{\mathrm{a})}$ & $\begin{array}{l}\text { Dogs are infected by ingesting the parasite eggs } \\
\text { excreted from foxes. }\end{array}$ & 447 & Wrong & 19.0 & 62.4 \\
\hline
\end{tabular}

a) Statements S1, S2, S5, S8, and S14 were given to only 451 owners.

b) The capital city of Hokkaido.

get the infection by ingesting the parasite eggs. However, this understanding was also vague, and $26.1 \%$ of the dog owners believed that the disease could be transmitted from human to human (see Table 1, S10). Moreover, $22.4 \%$ of the dog owners thought that the disease could be transmitted from infected pigs to humans (see Table 1, S11). In Hokkaido, approximately 2,000 infected pigs (prevalence: $0.2 \%$ ) are detected annually during meat inspections (data from the Hokkaido Government). However, like humans, pigs get the infection by ingesting the parasite eggs and then develop lesions in the liver, thus serve as accidental intermediate hosts. Therefore, pigs never excrete the parasite eggs and transmission from pigs to humans never occurs. The surveyed dog owners misunderstood another important aspect of the parasite life cycle: transmission never directly occurs between intermediate hosts, as from human to human or from pig to human.

Further confusion was elucidated by the answers to statement S13; $50.5 \%$ of the dog owners thought that dogs develop parasitic legions in the liver, indicating that the dog owners thought that dogs develop the same legions as humans.

In conclusion, this study revealed that dog owners residing in Hokkaido, an endemic area of the disease, who have a risk of infection by their dogs superficially understood the biology and epidemiology of E. multilocularis. Their understanding about the difference in the mode of disease transmission to dogs and humans was not completely clear, leading them to misbelieve that dogs can get the infection in the same way as humans. This vague understanding was presumably due to the complicated nature of the parasite life cycle in that two different hosts play different biological roles, namely, final and intermediate hosts are required for completing the life cycle of the parasite. From the point of view on a risk management, the understanding on it is of primary importance for individual dog owner to perform effective prophylactic measures against parasite infection in his/ her dogs. In order to do so, it is paramount that dog owners precisely understand the parasite life cycle and the events related to the risk of infection of dogs and humans. In this context, the role of veterinary practitioners is very important. We hope that the results of this simple questionnaire survey will be used by veterinary practitioners as a reference for explaining and enlightening dog owners of the disease process, then contribute to the performance of proper prophylactic measures against parasite infection by dog owners.

ACKNOWLEDGMENT. We acknowledge the members of the Hokkaido Small Animal Veterinary Association for their cooperation with this survey. We are also grateful to the staff of the Forum on Environment and Animals and to members of the Laboratory of Parasitology, Graduate School of Veterinary Medicine, Hokkaido University for their valuable support. This work was supported by the Japan Society for the promotion of Science (grant no. $10680772,11359002,15380205$ and 19580353) and by the Ministry of Health, Labour and Welfare, Japan (grant for Research on Emerging and Re-emerging Infectious Diseases).

\section{REFERENCES}

1. Budke, C.M., Campos-Ponce, M., Qian, W. and Torgerson, P.R. 2005. A canine purgation study and risk analysis for echinococcosis in a high endemic region of the Tibetan plateau. Vet. Parasitol. 127: 43-49.

2. Craig, P.S., Giraudoux, P., Shi, D., Bartholomot, B., Barnish, G., Delattre, P., Quere, J. P., Harraga, S., Bao, G., Wang, Y., 
Lu, F., Ito, A. and Vuitton, D. A. 2000. An epidemiological and ecological study of human alveolar echinococcosis transmission in south Gansu, China. Acta. Trop. 77: 167-177.

3. Deplazes, P. and Eckert, J. 2001. Veterinary aspects of alveolar echinococcosis-a zoonosis of public health significance. Vet. Parasitol. 98: 65-87.

4. Deplazes, P., Hegglin, D., Gloor, S. and Romig, T. 2004. Wilderness in the city: the urbanization of Echinococcus multilocularis. Trends Parasitol. 20: 77-84.

5. Gottstein, B., Saucy, F., Deplazes, P., Reichen, J., Demierre, G., Busato, A., Zuercher, C. and Pugin, P. 2001. Is high prevalence of Echinococcus multilocularis in wild and domestic animals associated with disease incidence in humans? Emerg. Inf. Dis. 7: 408-412.

6. Kamiya, M., Lagapa, J.T., Ganzorig, S., Kobayashi, F., Nonaka, N. and Oku, Y. 2007. Echinococcosis risk among domestic definitive hosts, Japan. Emerg. Inf. Dis. 13: 346-347.

7. Kamiya, M., Lagapa, J.T.G., Nonaka, N., Ganzorig, S., Oku, Y. and Kamiya, H. 2006. Current control strategies targeting sources of echinococcosis in Japan. Rev. Sci. Off. Int. Epiz. 25: $1055-1066$.

8. Nonaka, N., Kamiya, M., Kobayashi, F., Ganzorig, S., Ando, S., Yagi, K., Iwaki, T., Inoue, T. and Oku, Y. 2009. Echinococcous multilocularis infection in pet dogs in Japan. Vector Borne Zoonotic Dis. doi: 10.1089/vbz.2008.0097.

9. Nonaka, N., Kamiya, M. and Oku, Y. 2006. Towards the control of Echinococcus multilocularis in the definitive host in Japan. Parasitol. Int. 55: S263-S266.

10. Oku, Y. and Kamiya, M. 2003. Biology of Echinococcus. pp. 293-318. In: Progress of Medical Parasitology in Japan, vol. 8 (Otsuru, M., Kamegai, S. and Hayashi, S. eds.), Meguro Parasitological Museum, Tokyo.

11. Rausch, R.L. and Fay, F.H. 2002. Epidemiology of alveolar echinococcosis, with reference to St. Lawrence Island, Bering Sea. pp. 309-325. In: Cestode Zoonosis: Echinococcosis and Cysticercosis (Craig, P. and Pawlowski, Z. eds), IOS Press, Amsterdam. 